\title{
Fusões e incorporações: estudo dos dados financeiros de uma cooperativa de crédito após processo de aglutinação
}

\section{Mergers and acquisitions: study of the financial data of a credit union after the agglutination process}

\author{
DOI: $10.46814 /$ lajdv2n1-002
}

Recebimento dos originais: 01/01/2020

Aceitação para publicação: 10/01/2020

\section{Jaciara Xavier Pereira Ribeiro}

Doutoranda em Ciências da Educação pela Instituição Brasil de Educação e Pesquisa - IBEP, em parceria com a Universidade Nacional de La Plata e Universidade Del Sol

Instituição: Instituição Brasil de Educação e Pesquisa - IBEP, em parceria com a Universidade Nacional de La Plata e Universidade Del Sol - UNADES/IBEP/BRASIL

Endereço: UNADES - 14 De Mayo 462, Asunción, Paraguai/ IBEP - sede no Calçadão Arthur Bernardes, $n^{\circ}$ 152, Sala 06, Bairro Centro, Viçosa - MG - CEP 36.570- 061

E-mail: jaciaraxp@yahoo.com.br

\section{RESUMO}

O estudo tem como tema central as Fusões e Incorporações nas Cooperativas de Crédito, no qual foi analisado os dados financeiros após processo de aglutinação. Trata-se de um artigo teórico empírico. O objetivo geral deste artigo é de analisar os dados econômicos financeiros e de crédito de uma Cooperativa de Crédito Incorporadora, após processo de aglutinação. $\mathrm{Na}$ metodologia foram descritos os procedimentos metodológicos a serem utilizados, as unidades de análise e de observação, apresentação e análise dos resultados e estratégias/ações adotadas pela Cooperativa Incorporadora após processo. Os meios de investigação foram através de pesquisa documental e de caráter bibliográfica, conceituando termos relacionados ao Cooperativismo, com foco no Ramo de Crédito, Fusões e Incorporações. A unidade de análise foi uma Cooperativa de Crédito. A unidade de observação desta investigação foram os Relatórios Consolidados de Apuração de Resultados, Indicadores de e Ranking Financeiro do SICOOB CREDIMINAS, com base no período setembro/2010 e junho /2011. O objetivo geral foi alcançado, constatando que o processo a Incorporação proporcionou desenvolvimento financeiro e de crédito para a Cooperativa Incorporadora.

Palavras-chave: Cooperativa de Crédito, Fusões, Incorporações.

\begin{abstract}
The study has as its central theme the Mergers and Mergers in Credit Cooperatives, in which the financial data were analyzed after the agglutination process. This is an empirical theoretical article. The general objective of this article is to analyze the financial and credit economic data of a Cooperative of Credit Incorporation, after agglutination process. In the methodology were described the methodological procedures to be used, the units of analysis and observation, presentation and analysis of results and strategies / actions adopted by Cooperativa Incorporadora after process. The means of investigation was through documentary research and bibliographical character, conceptualizing terms related to Cooperativism, focusing on the Credit Branch, Mergers and Mergers. The unit of analysis was a Credit Union. The observation unit of this investigation were the Consolidated Reports of Results, Financial Indicators and Financial Ranking of SICOOB CREDIMINAS, based on the period September 2010 and
\end{abstract}


June 2011. The overall objective was achieved, noting that the Merger process provided financial and credit development for the Cooperativa Incorporadora.

Key words: Credit Cooperative, Mergers, Mergers.

\section{INTRODUÇÃO}

A Cooperativa trata-se de um segmento representado por organizações de pessoas que se unem, de forma voluntária, para cobrir necessidades econômicas, sociais e culturais comuns, por meio de uma empresa de propriedade coletiva e democraticamente gerida. Baseando-se em valores de ajuda mútua, responsabilidade, democracia, igualdade, eqüidade e solidariedade. Criadas com um propósito inicial de "defender" e proteger o sustento de comunidades das imperfeições do mercado (COOK e PLUNKETT, 2006).

O surgimento do Cooperativismo como empreendimento socioeconômico foi registrado na cidade de Rochdale, Inglaterra, em 21 de dezembro de 1844. Sob a crescente ameaça de substituição por máquinas a vapor e agravamento da miséria da classe operária, 28 tecelões se reuniram na busca por alternativas de trabalho. Criaram, assim, um pequeno armazém cooperativo de consumo: a "Sociedade dos Eqüitativos Pioneiros de Rochdale". Os membros das Cooperativas acreditam nos valores éticos da honestidade, transparência, responsabilidade social e preocupação pelo seu semelhante.

Segundo dados atualizados em agosto de 2010, fonte GEMERC/OCB-2009, o Brasil possui 7237 Cooperativas distribuídas em todos os estados com maior concentração nas regiões sul e sudeste do país. No que concerne à distribuição das cooperativas no território brasileiro, verifica-se maior concentração nas regiões de maior renda per capita-Sul e Sudeste, possivelmente favorecida pela maior quantidade de recursos financeiros disponíveis e pela maior quantidade de funcionários, públicos ou privados (IBGE, 2008).

As Cooperativas hoje estão presentes nos mais diversos setores e promovem, dentre outros benefícios, o acesso ao crédito, à saúde, à educação, à moradia, e ao mercado de trabalho, com responsabilidades sociais e ambientais (OCB, 2004). A Organização das Cooperativas Brasileiras (OCB) classifica as cooperativas do Brasil em treze ramos distintos de acordo com o setor econômico de sua atividade (OCEMG, 2008): Agropecuário, Consumo, Crédito, Educacional, Especial, Habitacional, Infraestrutura, Mineral, Produção, Saúde, Trabalho, Transporte e Turismo e lazer.

O artigo terá como foco, o Ramo de Crédito. As Cooperativas de Crédito surgiram no Brasil como entidades coletivas e mutualísticas de gestão dos recursos financeiros dos seus associados, sendo a primeira cooperativa do Brasil e da América Latina instalada em 1902, no município de Nova Petrópolis, Estado do Rio Grande do Sul (OCB, 2002). As Cooperativas de Crédito são Instituições Financeiras autorizadas e supervisionadas pelo Banco Central do Brasil, que exige das mesmas, rígidos controles, 
auditorias independentes e transparência na gestão. O ramo de Crédito no Brasil, em dezembro de 2009, segundo OCB apresentou 1100 Cooperativas de Crédito, 3.497 .735 cooperados e 42802 empregados. O setor Cooperativo de Crédito no Brasil atualmente concentra 2,3\% das operações de crédito do Sistema Financeiro Nacional - SFN (BANCO CENTRAL DO BRASIL, 2009). Segundo levantamentos feitos junto ao Banco Central do Brasil, a partir de 2002, observa-se a estabilidade no número de cooperativas de crédito e, a partir de 2007, ocorre ligeiro declínio do número de Cooperativas deste segmento. No mesmo período observa-se a evolução na participação relativa do Cooperativismo de Crédito no Sistema Financeiro Nacional em termos, por exemplo de Operações de Crédito, Empréstimos, Financiamentos entre outras e do Ativo Circulante e Realizável a Longo Prazo. Nesse contexto de estabilização, constatase um aumento no número de processos de fusão ou incorporação (F/I) entre Cooperativas de Crédito no mesmo período. Denomina-se fusão o processo a partir do qual duas ou mais empresas se unem para formar uma sociedade inteiramente nova, que absorverá os ativos e passivos das empresas que se uniram. Denomina-se incorporação - ou aquisições - o processo a partir do qual duas ou mais empresas se unem, mantendo a identidade de uma delas, geralmente aquela com maior volume de ativos ou cuja marca tem maior expressividade junto ao mercado em que atua. O processo de aglutinação entre Cooperativas é uma forte tendência no cooperativismo contemporâneo. Esse processo é considerado uma forma de aliança estratégica que essas organizações podem adotar para alavancar seus desempenhos empresariais, como aumento de participação no mercado, eliminação da concorrência predatória entre cooperativas de mesma atividade econômica, melhor controle de preços e custos, geração de melhores resultados e sobras e aumento de chance de sobrevivência do negócio cooperativo (OLIVEIRA, 2006).

O presente estudo concentra-se em analisar o desempenho econômico financeiro dos indicadores de desempenho de uma Cooperativa de Crédito, após processo de aglutinação. A Razão Social da Cooperativa de Crédito estudada não será divulgada neste artigo. Identificaremos a Cooperativa de Crédito, após processo de aglutinação como Cooperativa Incorporadora. O eixo norteador ou problema de pesquisa a ser estudado é expresso pela questão: Quais resultados econômicos financeiros a Cooperativa Incorporadora tem apresentado após processo de Aglutinação? O objetivo geral deste artigo é de analisar os dados econômicos financeiros e de crédito de uma Cooperativa de Crédito Incorporadora, após processo de aglutinação. Os objetivos específicos são de apresentar os resultados financeiros econômicos da Cooperativa de Crédito após processo de aglutinação e apontar as estratégias/ações tomadas pela Cooperativa Incorporadora após processo de aglutinação;

A pesquisa foi embasada nos anais do EnAnPAd, a qual verificamos a inexistência de publicações do tema, voltada a Aglutinação das Cooperativas de Crédito. As pesquisas foram realizadas no período compreendido entre 2007 a 2010, não sendo encontradas na área temática Finanças, nenhum artigo especificando sobre as fusões e incorporações, com análise dos dados financeiros de uma Cooperativa de 
Crédito após processo de aglutinação, justificando a necessidade do estudo sobre o assunto. Foram realizadas pesquisas bibliográficas e documentais sobre Cooperativismo de crédito, fusões, incorporações e aglutinações.

O presente texto está composto por esta seção introdutória, seguida do referencial teórico, metodologia, apresentação e análise dos dados, conclusões e referências.

\section{REFERENCIAL TEÓRICO}

\subsection{COOPERATIVISMO E COOPERATIVAS}

Cooperativismo é a associação de pessoas, de determinado segmento econômico ou social, com finalidade de desempenhar, em benefício comum, alguma atividade econômica, tendo como objetivo principal o desenvolvimento econômico e social. Os verbetes associativismo e cooperativismo estão interligados de forma inseparável. O Cooperativismo é tido como um dos principais instrumentos para a promoção de desenvolvimento econômico e social ao gerar e distribuir renda, e promover o capital social nas comunidades que o praticam (BIALOSKORSKI NETO, 2002).

O surgimento de uma cooperativa dá-se a partir de um acordo de colaboração empresarial firmado voluntariamente entre indivíduos, quando estes compreendem a importância de resolver coletivamente as necessidades econômicas experimentadas individualmente, de forma a obter benefícios mais expressivos do que aqueles obtidos pela ação isolada de cada um. Mesmo considerando o interesse econômico individual dos associados como o objetivo da cooperação, o indivíduo não é priorizado em detrimento do coletivo: ambos têm o mesmo grau de importância na cooperativa (VALADARES, 2003). Para Juvêncio, Andrade e Panzutti (2000, p. 25), "a empresa cooperativa deve ser entendida tanto como unidade de produção quanto em sua dimensão econômica e social, pois combina associação e empresa, ou seja, a associação de pessoas que se agrupam voluntariamente para atingir um fim comum, através da constituição de uma empresa dirigida democraticamente. " Por serem sociedades empresariais, elas também devem ser encaradas como um negócio vinculado diretamente às questões de mercado e de economia competitiva, devendo-se pautar pelas modernas técnicas de gestão empresarial para atingir os resultados preconizados pela cooperação (VALADARES, 2003).

O Sindicato e Organização das Cooperativas do Estado de Minas Gerais (OCEMG, 2008) define cooperativa como "uma associação autônoma de pessoas que se unem, voluntariamente, para satisfazer aspirações e necessidades econômicas, sociais e culturais comuns, por meio de uma empresa de propriedade coletiva e democraticamente gerida", conceito esse que preconiza o entendimento da Aliança Cooperativa Internacional (ACI). 


\title{
2.1.1 Os associados
}

Os associados são a base e a razão de existir de toda cooperativa. Em seu organograma, o exercício do poder parte inicialmente dos cooperados, nas assembléias, ou seja, o exercício do comando se dá de baixo para cima (MEINEN; DOMINGUES; DOMINGUES, 2002). Os donos da cooperativa disponibilizam seu capital para a empresa cooperativa, que, em contrapartida, produz serviços de que esses donos necessitam (VALADARES,2003). Polonio (1999) defende essa mesma perspectiva, ressaltando que as cooperativas de crédito permitem a partir da condição de seu proprietário ser também o usuário dos serviços prestados, a eliminação de intermediários nas operações financeiras, fazendo do tomador de crédito e do investidor a mesma pessoa.

\begin{abstract}
As ações pessoais de cada associado são as ações da cooperativa, mesmo porque servir o associado, que ao mesmo tempo é o proprietário e o tomador de serviços da instituição, é o meio pelo qual a sociedade pode alcançar o fim para o qual foi constituída. Sem as ações pessoais de cada associado a sociedade não pode prestar os serviços para os quais foi criada. A exemplo, em uma cooperativa de crédito, é inimaginável a concessão de empréstimos se não houver captação de recursos dos próprios associados. Enquanto uns contribuem com a aplicação de recursos, outros os tomam, mas isso durante um certo lapso de tempo, pois, em vista do permanente estado de cooperação, as figuras se alternam (LEITE; SENRA, 2005, p. 221).
\end{abstract}

Valadares (2003) afirma que a participação dos associados na tomada de decisão e na administração do negócio é a essência da gestão das cooperativas.

Nas cooperativas, os indivíduos se associam para utilizar os serviços da sociedade e não para obtenção de um dividendo de capital. Evidentemente, o que ocorre em uma cooperativa é que o cooperado ganha economicamente, mas não se apropria do capital de um terceiro (BIALOSKORSKI NETO, 1997).

\subsubsection{Cooperativas de Crédito}

Considerando a atual formatação do Sistema Financeiro Nacional, as cooperativas desse ramo são tidas como uma importante alternativa de acesso ao crédito e de inclusão no mercado financeiro por oferecerem à população em geral, em especial, ao pequeno empreendedor urbano e rural maior volume de recursos a juros menores que a média das taxas praticadas no mercado (OLIVEIRA, 2004). Isso é possível porque essa sociedade se preocupa em eliminar os intermediários na captação de recursos, nos investimentos e na concessão de empréstimo, fazendo do tomador e do investidor uma só pessoa (CECREMGE, 2008). Além disso, as cooperativas de crédito são importante mecanismo de regulação de mercado, uma vez que podem impedir, por meio da livre concorrência do mercado, que os bancos de varejo massificados pratiquem preços, taxas e juros abusivos (KRUEGER, 2004).

De acordo com Pinheiro (2008), cooperativas de crédito são Instituições Financeiras constituídas sob a forma de sociedade cooperativa, tendo por objeto a prestação de serviços financeiros aos 
associados, como concessão de crédito, captação de depósitos à vista e a prazo, além de outras operações específicas.

Segundo o presidente do Banco Central do Brasil, Alexandre Tombini, em entrevista a revista (SICOOB 2011, p.25), a importância do Cooperativismo de Crédito para o país concentra-se nos objetivos de prover e ampliar a oferta de serviços financeiros, fomentando, assim, a promoção da inclusão financeira e do desenvolvimento regional. (SICOOB 2011, p.25). Nota-se que a participação das cooperativas de crédito está em ascensão conforme estatística divulgada no dia 27 de julho de 2009 através do site do Banco Central do Brasil (www.bacen.gov.br)

Segundo (Pinheiro 2007):

As cooperativas de crédito são instituições financeiras constituídas sob forma de sociedade de pessoas que tem como objetivo a prestação de serviços aos associados, em forma de ajuda mútua, como concessão de empréstimos em diversas linhas de financiamento, captação de depósitos, cheques, prestação de serviços de cobrança, cartões de crédito, pagamentos, contas de investimento, além de outras operações específicas, enfim, uma série de produtos e serviços financeiros que atende às necessidades dos associados e que representa praticamente toda gama de operações financeiras permitidas a um banco. Em vista disso, as cooperativas de crédito estão sujeitas às mesmas condições de risco de intermediações financeiras inerentes aos bancos múltiplos e comerciais em geral.

O Quadro 1 apresenta algumas das principais diferenças entre os bancos e as Cooperativas de crédito:

\begin{tabular}{|c|c|}
\hline Bancos & $\begin{array}{l}\text { Cooperativas de crédito } \\
\end{array}$ \\
\hline 1. São sociedades de capital. & 1. São sociedades de pessoas. \\
\hline $\begin{array}{l}\text { 2. O poder é exercido na proporção do número de } \\
\text { ações. }\end{array}$ & $\begin{array}{l}\text { 2. O voto tem peso igual para todos (uma pessoa, um } \\
\text { voto). }\end{array}$ \\
\hline 3. As deliberações são concentradas. & $\begin{array}{l}\text { 3. As decisões são compartilhadas entre os } \\
\text { associados. }\end{array}$ \\
\hline $\begin{array}{l}\text { 4. O administrador é um terceiro (profissional de } \\
\text { mercado). }\end{array}$ & 4. O administrador é do meio (associado). \\
\hline 5. O usuário das operações é mero cliente. & 5. O usuário é o próprio dono (associado). \\
\hline $\begin{array}{l}\text { 6. O usuário não exerce qualquer influência na } \\
\text { definição do preço dos produtos. }\end{array}$ & $\begin{array}{l}\text { 6. Toda política operacional é decidida pelos } \\
\text { usuários/donos (associado). }\end{array}$ \\
\hline 7. Podem tratar distintamente cada usuário. & $\begin{array}{l}\text { 7. Não podem distinguir. o que vale para um, vale } \\
\text { para todos. }\end{array}$ \\
\hline 8. Priorizam os grandes centros. & $\begin{array}{l}\text { 9. Não restringem, tendo forte atuação nas } \\
\text { comunidades mais remotas. }\end{array}$ \\
\hline 9. Têm propósitos mercantilistas. & 9. A mercancia não é cogitada. \\
\hline $\begin{array}{l}\text { 10. A remuneração das operações e dos serviços não } \\
\text { tem parâmetro/limite. }\end{array}$ & $\begin{array}{l}\text { 10. O preço das operações e dos serviços visa à } \\
\text { cobertura de custos (taxa de administração). }\end{array}$ \\
\hline 11. Atendem em massa, priorizando o autosserviço. & $\begin{array}{l}\text { 11. O relacionamento é personalizado ou individual, } \\
\text { com o apoio da informática. }\end{array}$ \\
\hline $\begin{array}{l}\text { 12. Não têm vínculo com a comunidade e o público- } \\
\text { alvo. }\end{array}$ & $\begin{array}{l}\text { 12. Estão comprometidas com a comunidade e os } \\
\text { usuários. }\end{array}$ \\
\hline 13. Avançam pela competição. & 13. Desenvolvem-se pela cooperação. \\
\hline 14. Visam ao lucro por excelência. & 14. O lucro está fora do seu objeto. \\
\hline $\begin{array}{l}\text { 15. O resultado é de poucos donos / acionistas (nada } \\
\text { é dividido com os clientes). }\end{array}$ & $\begin{array}{l}\text { 15. O excedente (sobras) é distribuído entre os } \\
\text { usuários na proporção das operações de cada um. }\end{array}$ \\
\hline $\begin{array}{l}\text { 16. No plano societário, são regulados pela Lei das } \\
\text { Sociedades Anônimas. }\end{array}$ & 16. São reguladas pela Lei Cooperativista \\
\hline
\end{tabular}

Quadro 1: Comparativo banco e cooperativa de crédito

Fonte: LEITE e SENRA, 2005, p. 174. 
Segundo Polonio(1999), as principais vantagens em ser membro associado de uma cooperativa de crédito são assim elencadas: a) acesso ao crédito a juros mais baixos; b) acesso aos serviços financeiros com taxas menores; c) melhores condições de retorno de investimentos e aplicações; d) orientação financeira; e) responsabilidade limitada à cota de capital integralizada; f) dupla personalidade em ser dono e usuário do empreendimento; g) participação nos resultados, proporcional às operações na cooperativa.

Para representar os associados, agir em seu nome e fiscalizar a administração de seus dirigentes, as cooperativas de crédito devem compor os seguintes órgãos sociais em sua estrutura administrativa, que é previsto também pela lei das cooperativas (BRASIL,1971): a) Assembléia Geral, o órgão máximo em poder de decisão numa cooperativa. As decisões de interesse da cooperativa e dos associados, inclusive as eleições de conselhos e a destinação de sobras, são definidas pela maioria dos votos, e cada associado tem direito a um voto; b) Conselho de Administração, cuja principal atribuição é gerir a cooperativa conforme as determinações dos associados decididas em assembléias. Os membros desse conselho são eleitos para mandatos nunca superiores a quatro anos por determinação legal; c) Conselho Fiscal, cuja função é fiscalizar os atos administrativos da cooperativa por meio dos registros contábeis e financeiros, livros, documentos e demais instrumentos que contribuam para acompanhar e controlar a gestão e o patrimônio da cooperativa, garantindo a transparência e eficiência da administração do empreendimento.

\subsection{FUSÕES E INCORPORAÇÕES}

As organizações buscam, nas operações de Fusões e Aquisições (F\&A), novo posicionamento estratégico, sinergia na economia de escala, redução de custos, aumento de receitas, redução do risco do negócio, aumento de participação de mercado, criação de valor para os sócios, melhor acesso a mercados e desenvolvimento de novas tecnologias. Essas combinações permitem as organizações ganharem em flexibilidade e criarem novas oportunidades de sobrevivência de seus negócios (NAPIER, 1989; NADLER, 1994; CARTWRIGHT; COOPER,1995; EVANS; PUCIK; BARSOUX, 2002; RODRIGUES, 1999; ROSSON; BROOKS, 2004; KLOECKNER,1994).

Em estudo sobre F/I entre instituições bancárias na segunda metade da década de 1990, Sobek (2000), p. 29), afirmou que, entre os objetivos dos bancos em buscar as fusões estão: “[...] reduzir custos, estender a gama de produtos e serviços, aumentar a participação no mercado, participar dos processos de privatização (em economias emergentes), diversificar riscos e áreas de atuação e recuperar a solvência". A busca de recuperação da solvência, outro fator citado por Sobek (2000), como motivador de fusões e aquisições entre bancos, ocorre quando a situação financeiras de uma empresa é desfavorável e os riscos de liquidez e de continuidade são altos. A fusão ou a incorporação pode ser uma alternativa significativa mais favorável do que a falência ou a concordata. Frohlich e Kavan (2000) chegaram a conclusões 
semelhantes às de Sobek (2000) acerca das razões para F/I entre bancos. Segundo os autores, a melhora no desempenho econômico financeiro é um fator motivador preponderante, e é reflexo, genericamente, das reduções de custos e aumento das receitas. Os autores citam a criação de economia de escala, expansão geográfica, a busca do aumento combinado do tamanho da instituição e da gama de produtos oferecidos e ganho de poder de mercado como fatores motivadores específicos. Duas empresas que se fundem podem reduzir certos tipos de despesas administrativas e logísticas. Suárez, Gorbaneff e Beltrán (2009), em estudo de caso sobre a fusão entre os bancos colombianos Davivienda, Bansuperior e Bancafé, pesquisaram na literatura acadêmica mundial os fatores apontados como motivadores de processos de F/I de bancos. Alguns dos fatores mais importantes levantados pelos autores foram a sinergia, o crescimento, o ganho de mercado e os ganhos de escala.

\subsubsection{Aglutinação, Fusões e Incorporações no Cooperativismo de Crédito}

A fusão entre cooperativas implica a constituição de uma nova sociedade cooperativa da que sucederá os direitos e as obrigações das sociedades originárias e na declaração da extinção dessas. Em outras palavras, a constituição de uma nova sociedade cooperativa se dá simultaneamente com a extinção das fusionadas. (KRUEGER; MIRANDA, 2007). Os processos de incorporação entre cooperativas, por sua vez, implicam a absorção, pela sociedade incorporadora, do patrimônio, dos direitos, das obrigações, dos associados e empregados das sociedades incorporadas.

Essas referências são condizentes às organizações cooperativas assim como são para as empresas com fins mercantilistas. A Lei Federal n. 5.764/1971, em seu Capítulo X, Artigo 57 ao 59, prevê sobre a aglutinação de cooperativas através de fusões e incorporações, unificando seus quadros de associados, seus patrimônios, seus passivos e ativos. Particularmente, as cooperativas de crédito devem ter autorização do Banco Central do Brasil para executarem esses processos. Assim como as empresas com fins mercantilistas, as cooperativas buscam incessantemente o crescimento e o fortalecimento de seus negócios e sua sobrevivência no mercado. Essas condições podem ser sustentadas principalmente pelo aprimoramento e pela modernização dos meios de produção e distribuição dos bens e serviços para os cooperados. Fusões e incorporações entre sociedades cooperativas seriam formas de se alcançarem esses patamares, buscando a convergência de interesses dos associados de uma ou mais organizações cooperativistas (KRUEGER; MIRANDA, 2007).

Bauer, Miles e Nishikawa (2009), em estudo específico sobre processos de F/I entre Cooperativas de crédito norte-americanas, chegaram à conclusão de que os fatores que motivam esses processos em cooperativas são diferentes do que ocorre com bancos. Estes tendem a se fundir quando o valor combinado das firmas é maior do que seus valores de mercado individuais. Nas Cooperativas de crédito, os acionistas, isto é, os cooperados, somente percebem benefícios nas fusões caso elas impliquem 
melhora imediata nas taxas de aplicação e empréstimo aos associados, ou seja, eles próprios. Os autores utilizam demonstrativos financeiros das cooperativas de crédito dos anos 1994 a 2004, fornecidos pela NCUA (Nacional Credit Union Administration), organismo de regulação e controle de cooperativas de crédito dos Estados Unidos.

Garden e Ralston (1998), em estudos sobre a realidade australiana, concluem que as cooperativas de crédito que passaram por processos de F/I, geralmente ganham eficiência, mas esse ganho não é necessariamente conseqüência direta desses processos. Acrescentam ainda que os gerentes de cooperativas não deveriam lançar mão das F/I como forma de reduzir custos, já que essa relação de causa e efeito não ficou clara. Além disso, concluem que as F/I não implicam ganhos para os associados. Hoshino (1988) empreendeu análise dos processos de fusão entre instituições financeiras, incluindo cooperativas e outros tipos.

Segundo Oliveira (2006), o processo de fusões e incorporações entre cooperativas é uma forte tendência no cooperativismo contemporâneo. Esses processos são considerados uma forma de aliança estratégica que essas organizações podem adotar para alavancar seus desempenhos empresariais, como aumento de participação no mercado, eliminação da concorrência predatória entre cooperativas de mesma atividade econômica, melhor controle de preços e custos, geração de melhores resultados e sobras e aumento de chance de sobrevivência do negócio cooperativo.

\subsubsection{Aglutinação na visão do Associado}

Há de se considerar, no entanto, que esses processos de aglutinação de cooperativas provocam mudanças estruturais nas relações sociais e de influência entre todos aqueles que são afetados direta ou indiretamente em função dos conflitos de interesses que são gerados, notadamente entre os associados das organizações envolvidas. Esses associados assumem a posição de defesa de seus interesses patrimoniais e, principalmente, operacionais, uma vez que seu maior interesse, na maioria das vezes, não está no capital investido na sociedade, mas nos produtos e serviços que a cooperativa lhes oferece (KRUEGER; MIRANDA, 2007).

Acrescem-se às questões de ordem operacional e financeira aquelas associadas aos vínculos emocionais dos associados com suas cooperativas de origem, o que pode obscurecer o processo de tomada de decisão, quando este busca exclusivamente à maximização dos resultados econômicos provenientes da união de forças dessas sociedades: 
Há a perspectiva emocional de perda de influência e, portanto, de perda de benefícios não econômicos em serviços e atenção [...]. A inexistência da distribuição de sobras e de retorno de seu capital social investido em longo prazo faz com que a dimensão não tangível de benefícios de bem-estar, de atenção, de influência e convívio possa ser maior que os possíveis benefícios econômicos no futuro de uma estratégia de alianças e fusões. Assim, também os membros não entendem de modo transparente os benefícios dessa estratégia (BIALOSKORSKI NETO, 2006, p.146).

Verifica-se que os associados podem enxergar, diante da junção de suas cooperativas e da conseqüente mudança nas estruturas das relações sociais, a perda de identidade e de influência, o que gera a resistência à mudança e o afastamento do associado da participação e do convívio direto na gestão do empreendimento cooperativo. Configura-se, assim, também como objetivo do cooperado, o acesso a áreas de influência pessoal, benefícios não declarados e intangíveis, por se tratar de capital simbólico (BOURDIEU, 1992). A possibilidade de resistência a esses movimentos de aglutinação de cooperativas por parte de seus associados, de certa forma, traduz uma matriz de interesses financeiros, ganhos operacionais e sistemas relacionais, fatores que sugerem ampla gama de jogos de interesses, incluindo os não-expressos ou formalizados.

\section{METODOLOGIA}

Neste capítulo, serão descritos os procedimentos metodológicos a serem utilizados, as unidades de análise e de observação, apresentação e análise dos resultados e estratégias/ações adotadas pela Cooperativa Incorporadora após processo de aglutinação. Quanto aos meios de investigação, para a realização deste estudo, tornou-se necessário o desenvolvimento de uma pesquisa documental e de caráter bibliográfica, conceituando termos relacionados ao Cooperativismo, com foco no Ramo de Crédito, Fusões e Incorporações e aglutinações. A unidade de análise foi uma Cooperativa de Crédito, situada na Zona da Mata Mineira, no qual chamaremos de Cooperativa Incorporadora. A Incorporação ou Aglutinação ocorreu entre duas Cooperativas de Crédito mineiras. Uma das Cooperativas apresentavam dificuldades financeiras, sendo incorporada pela outra, que apresentava capacidade Financeira e Administrativa. A unidade de observação desta investigação foram os Relatórios Consolidados de Apuração de Resultados, Indicadores de Desempenho emitidos pelo Sistema de Informações Gerenciais (SIG Net) e Ranking Financeiro do SICOOB CREDIMINAS, disponibilizado mensalmente pela Central. Foram realizados comparativos entre estes relatórios "antes" e "após" processo de aglutinação. Os relatórios analisados são de competência mês setembro/2010 e junho /2011. A análise dos dados econômicos financeiros e de crédito após processo de aglutinação, foram realizadas, apenas utilizando os dados da Cooperativa Incorporadora. 


\subsection{APRESENTAÇÃO DOS RESULTADOS}

Os dados secundários foram tratados por meio de um processo analítico descritivo, com base nos objetivos específicos. As informações foram analisadas, caracterizando as unidades de observação.

Após realização dos comparativos entre relatórios de competência setembro/2010 e junho /2011, “antes” e "após” processo de aglutinação, apresentamos os dados, que serão analisados.

Após o processo de aglutinação a "Cooperativa incorporadora", apresentou crescimento nos depósitos totais de 76,10\%. Crescimento de 33,38\% nos Repasses/Empréstimos. O Patrimônio Liquido Ajustado (PLA) apresentou um crescimento de 39,72\%. Ocorreu crescimento de $64,17 \%$ na carteira de Operações de Crédito. As Disponibilidades apresentaram crescimento de 60,68\% sendo composta pelo Caixa e Centralizações Financeiras. O crescimento no Permanente foi de 42,37\%. As rendas de Serviços também apresentaram um crescimento de $23,47 \%$.

O número de Postos de Atendimento Cooperativo (PAC's) passou de dez unidades para dezoito, um crescimento de $80 \%$. Após análise de viabilidade econômica, foram encerradas atividades de dois PAC's, estando atualmente com dezesseis unidades. Estudos para abertura de novos PAC's estão sendo realizados. No número de associados ativos ocorreu um crescimento de 65,04\%. No mês de junho/2011, o número de associados da Cooperativa incorporadora foi de 10112 associados.

As Despesas Administrativas apresentaram uma redução de 22,71\%. Ocorreu um reduz 6,61\% do número de funcionários. A Cooperativa Incorporada tinha 44 funcionários, sendo demitidos após processo de aglutinação 24 funcionários. As despesas pagas em Honorário do Conselho/Diretoria foram reduzidas em $81,31 \%$ e as despesas de pessoal apresentaram redução de 2,44\%.

No Ranking Financeiro do Sistema, a Cooperativa Incorporadora melhorou 21 posições, passando de $33^{\circ}$ para $21^{\circ}$. Este Ranking tem como base os valores de Depósito, PLA e Operações de Crédito.

\subsection{ANALISE DOS DADOS}

Os dados apresentados demonstram que o processo de aglutinação foi positivo para a Cooperativa Incorporadora, que apresentou crescimento em seus Depósitos, Repasses e Empréstimos, Patrimônio Líquido Ajustado, carteira de Operações de Crédito, Disponibilidade, Permanente, Renda de Serviços, número de PAC'S e Associados.

Ocorreu redução nas Despesas Administrativas. Com o processo de aglutinação, a Cooperativa Incorporada, passou a ser um PAC, da Cooperativa Incorporadora (Sede), com isto, foi possível a unificação do centro administrativo, que ficou localizado na cidade sede, o que provocou várias demissões do quadro de funcionários, grande parte da Cooperativa Incorporada, reduzindo as despesas de pessoal, mesmo com as readequações salariais e promoções de funcionários. A redução das despesas pagas em Honorário do Conselho/Diretoria, se justifica pela diminuição do número de membros do 
Conselho de Administração e fiscal após processo de aglutinação. A pesquisa comprova que nos processos de F\&A entre empresas, a tendência de redução de despesas, principalmente no setor pessoal ocorre, devido à redução do quadro de funcionários.

A Cooperativa Incorporadora manteve-se no período analisado, enquadrada quanto ao Limite Global, Índice de imobilizado, Limite de diversificação de risco, concentração de deposito e concentração de risco, não sendo prejudicada após processo de aglutinação, porém a classificação de Risco PROAF passou de Baixo Risco Longo Prazo (BRLP) para Baixo Risco Médio Prazo (BRMP).

\subsubsection{Estratégias / Ações}

Após processo de Aglutinação, a “Cooperativa Incorporadora” adotou algumas estratégias, sendo: Conscientização dos associados e sociedade sobre o processo de Aglutinação, através de Assembléias Gerais, cafés empresariais e veículos de Comunicação; Padronização da Marca; Redução do número de membros do Conselho de Administração e Fiscal, através da demissão dos Conselheiros da Cooperativa Incorporadora; Governança Corporativa por parte da Diretoria-Executiva; Diversas reuniões, treinamentos e reciclagem envolvendo Diretoria e funcionários; Centralização das decisões e unificação do Centro Administração na Cidade sede da Cooperativa Incorporadora; Padronização dos processos, através de treinamento e reciclagem entre funcionários; Promoção de funcionários dentro do quadro, principalmente para área Gerencial e Administrativa; Demissões de funcionários que não apresentavam perfil profissional, ou cuja remuneração estava acima dos salários adotados pela Cooperativa Incorporadora, o que poderia gerar ações trabalhistas no futuro; Contração de funcionários para substituição dos demitidos. Readequação salarial dos funcionários de acordo com Plano de Cargos e Salários do Sistema; Investimentos em Treinamento e Capacitação dos funcionários, principalmente do quadro gerencial; Promoção de um Gerente de Agencia ao Cargo de Gerente de Negócio para orientar e alavancar os negócios dos Postos de Atendimento da Cooperativa Incorporada, que apresentava dificuldades financeiras antes da aglutinação; Fechamento de dois Postos de Atendimento Cooperativo da Cooperativa Incorporada, que não apresentavam viabilidade econômica; Realização de estudos para abertura de novos PAC's; Projeto Empresarial, com implantação de metas para alavancar os Depósitos, a carteira de Operações de Crédito, o Patrimônio Líquido Ajustado e a Redução das Despesas Administrativas, além de outras ações.

\section{CONCLUSÕES}

O Cooperativismo é tido como um dos principais instrumentos para a promoção de desenvolvimento econômico e social ao gerar e distribuir renda. As Cooperativas hoje estão presentes nos mais diversos setores e promovem vários benefícios. As cooperativas de crédito apresentam um cenário 
em que os processos de Fusão e Incorporação configuram-se como uma tendência irreversível, sendo considerada a solução mais adequada para se fortalecerem, se tornando competitivas, mantendo-se no mercado por meio da união de esforços e de recursos, com uma estrutura enxuta e gestão eficaz. Os resultados da pesquisa fortaleceram os conceitos mencionados no referencial teórico. As cooperativas de crédito que passaram por processos de F/I, geralmente ganham em eficiência e eficácia, onde os processos de fusões e incorporações entre cooperativas é uma forte tendência no cooperativismo contemporâneo, sendo considerados como uma forma de aliança estratégica que essas organizações podem adotar para alavancar seus desempenhos empresariais, aumentando sua participação de mercado, minimizando custos com a geração de melhores resultados e aumentando a chance de sobrevivência do negócio cooperativo. Os processos de aglutinação de cooperativas provocam mudanças estruturais nas relações sociais e de influência entre todos aqueles que são afetados direta ou indiretamente em função dos conflitos de interesses que são gerados. Como vantagens do processo de F/I destacam-se a redução dos custos, a gama de produtos e serviços são ampliados, aumentando a participação no mercado, ocorrendo a diversificação de risco, além de melhorar o desempenho econômico financeiro com a reduções de custos e aumento das receitas.

Como limitação do estudo, destaca-se o fato de ter utilizado como meios de investigação, apenas pesquisas documentais, com a utilização de dados secundários e de caráter bibliográfica. Como sugestão para próximos estudos, a realização de uma pesquisa quantitativa e qualitativa, através de aplicação de questionários e entrevista, objetivando medir a percepção dos conselheiros, funcionários e associados, sobre o processo de Fusões e Incorporações nas Cooperativas de Crédito. Outra limitação do estudo é o fato de ter sido realizado em apenas uma Cooperativa Incorporadora. Em estudos futuros, outras Cooperativas que passaram pelo processo de Aglutinação, nas condições de Incorporadora e Incorporada poderiam ser analisadas. Diante destas limitações, fica o estudo aberto para que sejam realizadas novas pesquisas sobre o assunto abordado. 


\section{REFERÊNCIAS}

ANPAD. Associação Nacional de Pós-Graduação e Pesquisa em Administração. Disponivel em <http://www.anpad.org.br>. Acessos em jun. 2011

BANCO CENTRAL DO BRASIL. Relatório de Evolução do SFN. Participação das instituições do segmento bancário nas operações de crédito deste segmento. Disponível em:<http://www.bcb.gov.br/htms/Deorf/r200612/quadro16.asp?idpai=REVSFN200612> Acesso em: 27 fev. 2009.

BAUER, Keldon; MILES, Linda; NISHIKAWA, Takeshi. The effect of mergers on credit unior performance. Journal of Banking and Finance, 2009, v. 33, n.12, p. 2.267-74. Jun. 2009.

BRASIL. Legislação Cooperativista e Resoluções do Conselho Nacional de Cooperativismo, Lei Federal n.5.764 de 16 de dezembro de 1971, que define a política nacional de cooperativismo, institui o regime jurídico das sociedades cooperativas e dá outras providências. Brasília, 1971. Disponível em: <www.planalto.gov.br/ccivil_03Leis/15764.htm.> Acesso em: 10 mar. 2009.

BIALOSKORSKI NETO, Sigismundo. Aspectos econômicos das cooperativas. Belo Horizonte: Mandamentos, 2006.

BIALOSKORSKI NETO, Sigismundo. Gestão do agribusiness cooperativo. In: BATALHA, Mário O. (Coord.). Gestão agroindustrial: GEPAI: Grupo de Estudos e Pesquisas Agroindustriais. São Paulo: Atlas, 1997.

BIALOSKORSKI NETO, S. Estratégias e Cooperativas Agropecuárias: um ensaio analítico.124 In: Seminário de Política Econômica em Cooperativismo e Agronegócios da UFV.Viçosa, 2002

BORGES, Carlos Eduardo Avila ; SILVA, Georgina Alves Vieira; CORRÊA, Maria Laetitia. Mudança na percepção de valor em cooperativas de crédito pós-aglutinação: um estudo de caso. Revista Gestão e Planejamento: Salvador|V. 10 |N.2 |p. 157-178, jul./dez. 2009

BOURDIEU, Pierre. O poder simbólico. Rio de Janeiro, Bertrand Brasil, 1992.

CARTWRIGHT, Sue; COOPER, Cary. L. Organizational marriage: "hard" versus "soft" issues? School of Management, UMIST, Personnel Review, Manchester, UK, v. 24, n. 3, 1995.

CECREMGE. Central das Cooperativas de Economia e Crédito de Minas Gerais. Belo Horizonte, 2008. Disponível em: <www.cecremge.org.br> . Acesso em: 14 mar. 2008.

COOK, M.L.; PLUNKETT, B. Collective Entrepreneurship: An Emerging Phenomenon in Producer- Owned Organizations. Journal of Agricultural and Applied Economics, Griffin, v. 38, p. 421-428, 2006

EVANS P., PUCIK V., BARSOUX J.L. The global challenge: frameworks for international human resource management. Boston: McGraw-Hill, 2002.

FROHLICH, C; KAVAN, B. Na examination of bank merger activity: a strategic framework content analysis. Academy and Financial Studies Proceedings, 2000. 
GARDEN, A. Kaylee;RALSTON, E. Deborah. The x-efficieney an allocative efficiency effects of credit union mergers. Toowoomba: University of Southern Queensland. 1998.

HOSHINO, Yasuo: An Analysis of Mergers among the Credit Associations in Japn. Rivista Internacionale di Scienze Economiche e Commerciali (International Review of Economics and Business) v. 35, n.2, p. 135156.1988.

IBGE. Instituto Brasileiro de Geografia e Estatística, Disponível em: http://www.ibge.gov.br. Acesso em 03 mar. 2011

JÚNIOR, Ewerton Luiz Veloso Júnior; Estudo do Desempenho de Fusões e Incorporações entre Cooperativas de Crédito no Brasil. (Dissertação UFMG), 2011.

JUVÊNCIO, Fernanda de Castro; ANDRADE, Geraldo V. de; PANZUTTI, Ralph. Cooperativismo ao alcance de todos. São Paulo: OCESP, 2000.

KLOECKNER, Gilberto de Oliveira. Fusões e aquisições: motivos e evidência empírica. Revista de Administração, São Paulo, v. 29, n. 1, p. 42-58, jan./mar. 1994.

KRUEGER, Guilherme. Ato Cooperativo e Seu Adequado Tratamento Tributário. Belo Horizonte: Mandamentos, 2004.

KRUEGER, Guilherme; MIRANDA, André Branco de. Comentários à legislação das sociedades cooperativas - Tomo I. Belo Horizonte: Mandamentos, 2007

LEITE, Jacqueline Rosadine de Freitas; SENRA, Ricardo Belízio de Faria. Aspectos Jurídicos das Cooperativas de Crédito. Belo Horizonte: Mandamentos, 2005.

MEINEN, Ênio; DOMINGUES, Jefferson Nercolini; DOMINGUES, Jane Aparecida Stefanes. Cooperativas de Crédito no Direito Brasileiro. Porto Alegre: Editora Sagra Luzzatto, 2002.

NADLER, David. Arquitetura organizacional. Rio de Janeiro: Campus, 1994.

NAPIER, N. K. Mergers and Acquisitions: Human Resource Issues and Outcomes. A Review and Suggested Typology. London, Journal of Management Studies, 26, p. 271-287, 1989.

OCB. Organização das Cooperativas Brasileiras. Disponível em: <http://www.sescoop.org.br>Acesso em: 01 jul. 2011.

OCEMG. Sindicato e Organização das Cooperativas do Estado de Minas Gerais. Anuário do Cooperativismo Mineiro - Maiores Cooperativas de Minas Gerais - 2008. Belo Horizonte: Ocemg, 2008.

OLIVEIRA, Djalma de Pinho Rebouças de. Manual de gestão das cooperativas: uma abordagem prática - 3. ed. São Paulo: Atlas, 2006.

OLIVEIRA, Mauro José. Governança Corporativa: uma alternativa para a gestão do Cooperativismo de Crédito. Brasília: Banco Central do Brasil, 2004.

PINHEIRO, Marcos Antonio Henriques. Cooperativas de Crédito: história da evolução normativa no Brasil. 5. ed. Brasília: BCB, 2007. 
PINHEIRO, M. A. H.; Cooperativas de Crédito História da evolução normativa no Brasil. Banco Central do Brasil, 2008.

POLONIO, Wilson Alves. Manual das Sociedades Cooperativas. São Paulo: Atlas, 1999.

REVISTA SICOOB. Tombina Destaca a importância do Cooperativismo de crédito. SICOOB Confederações: Brasilia, 2011.

RODRIGUES, S. B. Formação de Alianças estratégicas em países emergentes: O caso Brasil - China. In:

RODRIGUES, S. B. Competitividade, alianças estratégicas e gerência internacional. São Paulo: Atlas, 1999.

ROSSON, Phillip; BROOKS, Mary R. M\&A and corporate visual identity: an exploratory study. Corporate Reputation Review, v. 7, n. 2, p. 181-194, 2004.

SOBEK, Otto. Bank mergers and acquisitions.Biatec. Eslováquia, 2000.

SUÁREZ, Ingrid; GORBANEF, Yuri; BELTRAN, Jorge. Motivos de fusiones y grupos econômicos: El caso Davivienda - Bansuperior - Bancafé.Bogatá: Departamento de Administración, Facultad de Ciencias Econômicas y Administrativas, Pontificia Universidad Javeriana, 2009.

VALADARES, José Horta. Estrutura e estratégia institucional: formação de campo organizacional e isomorfismo no cooperativismo de crédito rural de Minas Gerais. Dissertação (Doutorado em Desenvolvimento, Agricultura e Sociedade) Seropédica: UFRJ, 2003. 